the Urgent, while I occupied a second boat nearer to the stern of the ship. He cast the plate as a mariner heaves the lead, and by the time it had reached me, it had sunk a considerable depth in the waler. In all cases the hue of this plate was green, not, of course, a pure green, but a mixture of green and blue; and when the sea was of the darkest indigo, the green was the most vivid and pronounced. I could notice the gradual deepening of the colour as the plate sank, but at its greatest depth in indigo water the colour was still a blue green.

"Other observations confirmed this one. The Urgent is a screw steamer, and right over the blades of the screw there was an orifice called the screw-well, through which you could look from the poop down upon the screw. 'The surface glimmer which so pesters the eye was here in a great measure removed. Midway down a plank crossed the screw-well from side to side, and on this I used 10 place myself to observe the action of the screw underneath. The eye was rendered sensitive by the moderation of the light; and still further to remove all disturbing causes, Lieutenant Walton had the great kindness to have a sall and tarpaulin thrown over the mouth of the well. Underneath this I perched myself, and watched the screw. In an indigo sea the play of colours was indescribably beautiful, and the contrast between the water which had the screw-blacles for a background, and that which had the bottom of the ocean as a background, was extraordinary. The one was of the most brilliant green, the other of the most lustruus uliramarine. The surface of the water aloove the screw. blade was always ruffled. Liquid lenses were thus formed, by which the coloured light was withdrawn from some places and concentrated upon others. The screw-blades in this case replaced the plate in the former case, and there were other instances of a similar kind. The hue from an indigo sea uas alkays green at a cerlain depth below the surface. The white belies of the porpoises showed the same hue, varying in intensity as the creatures swung to and fro between the surface and the deeper water. In a rough sea the light which had penetiated the summit of a wave sometimes reached the eye. A beautiful green cap was thus placed upon the wave when the ship was in indigo water.

"But $\mathrm{H}_{\mathrm{O}} \mathrm{w}$ is this culour to be connected with the suspended particles? Take the dinner-plate which showed so brilliant a green when thrown into indigo water. Suppose it to diminish in size until it reached an almost microscopic magnitude. It would still behave substantially as the larger plate, sending to the eye its modicum of green light. If the plate, instead of being a large coherent mass, were ground to a powder sufficiently fine, and in this condition diffused through the clear sea water, it would send green to the eye. In fact, the suspended particles which the home examination revealed in green sea water act in all t ssential particulars like the plate, or like the screw-blades, or like the foam, or like the bellies of the porpoises. When too gross, or in too great quantity, the suspended particles thicken the sea itself visibly. But when sufficiently small, but not ton small, and when sufficiently diffused, they do not sensibly interfere with the limpid greemness of the sea it:elf. They then require the sironger and more delicate test of the concentrated lumirous beam to reveal their presence,"

\section{THE TEMPERATURE OF THE SUN}

PROF. NEWCOMB, in reviewing P. A. Secchi's work on the Sun, shows that if the temperature reached $10,000,000^{\circ}$ Cent, as asserted by the author of "Le Soleil," the earth would speedily be reduced to vapour. In answer to this objection Yére Secchi urges, "that a body may have a very high temperature and yet radiate but vesy liule;" contending that "a thermometer dipped inside the solar envelope in contact with the photosphere," would indicate the temperature mentioned. $\mathrm{He}$ adds, "This high temperature, besides, is really a virtual temperature, as it is the amount of radiaiion received from all the transparent strata of the solar envelope, and this body at the outer shell must certainly be at a lower temperature." What iniormation is intended to be conveyed by the statemt nt that $10,000,000^{\circ}$ Cent. "is really a virtual temperature," on the ground that it is the "amount of radiation received from all the transparent strata" outside of the photosphere, I will not attempt to explain; but I propose to show that a thermometer dipped inside the solar envelope in contact with the photosphere, cannot possibly indicate the enormous temperature of $10,000,000^{\circ}$ Cent. assumed by Pére Secchi. The assertion that "a. body may have a very high temperature and yet radiate but very little," were it correct with reference to the photosphere, does not affect the question. It is of no consequence wheth $\mathrm{r}$ the sun's photosphere belongs to the class of active or sluggish incandescent radiators imagined by the distinguished savan; the temperature of the radiant surface, not its capacity to radiate more or less copiously, is the problem to be solved. Accordingly the following statement is intended to show that the temperature of the sun's photosphere at the point where the author of "Le Soleil" supposes his thermometer to be applied, cannot much exceed $4,000,000^{\circ} \mathrm{Fahr}$. Observations conducted in lat. $40^{\circ} 42^{\prime}$, with an actinometer (a drawing of which bas been published in Engineering) have enabled me to ascertain, with desirable accuracy, the intensity of solar radiation for each degree of the sun's zenith distance from $r 7^{\circ}$ to $75^{\circ}$. The atmospheric depth at the first mentioned zenith distance being only 0.046 greater than the vertical atmospheric depth, I have demonstrated, by prolonging the curve constructed agreeable to the observations referred to, that the intensity of solar radiation on the ecliptic is $67.20^{\circ} \mathrm{Fahr}$. at the time when the earth passes the aphelion. The accompanying table, the result of two years of observations, shows the atmospheric depth and the intensity of solar radiation for each degree from the vertical to $75^{\circ}$ zenith distance. The ratio of diminution of intensity of the radiant heat during the passage of the rays through the atmosphere being accurately defined by this table, it has been easy to calculate that the amount of retardation of the radiant heat on the ecliptic is 0.207 or $17.64^{\circ} \mathrm{Fahr}$. Adding this loss of energy to the amount of observed radiant heat, it will be found that the intensity of solar radiation at the boundary of our atmosphere when the earth passes the aphelion corresponds with a thermometric interval of $17.64+$ $67^{\circ} 20=84^{\circ} 84^{\circ}$ on the Fahrenheit scale. Now, the aphelion distance of the earth is 2 I 8.1 times greater than the radius of the sun's photosphere; hence, basing our calculations on the established truth that the intensities are inverstly as the areas over which the rays are dispersed, we prove that the temperature of the photosphere is $218 \cdot 1^{2} \times 84^{\circ} 84^{\circ}=4,035,584^{\circ} \mathrm{Fahr}$. And if we then adi. the amount of loss of intensity attending the passage of the rays through the solar envelope, we establish, with absolute certainty, the temperature to which a thermometer will be subjected if "dipped inside the solar envelope in contact with the photesphere."

With reference to the retardation of the rays in passing through the solar envelope, we possess practical data of such a nature that the solution of the problem is by no means mere hypothesis. We know that the density" of atmospheric air would be reduced to $\overrightarrow{s 00}+$ of the ordinary density if subjected to a temperature of $4,000,000^{\circ}$ Fahr.; herce, if we assume that the solar envelope consists chiefly of hydrogen, it may be shown, due allowance being made for the superior attraction of the sun's mass, that the density of the terrestrial atmosphere at equal depth from the boundary is fuliy 2,000 times greater than that of the solar envelope. Accordingly, as the sun's rays lose only $17^{\circ} 6^{\circ}$ in passing vertically through our cold a!mosphere, it may be demonstrated that the loss of energy during the passage of the rays through a transparent solar envelope 80,000 miles in depth from the photosphere, cannot exceed $0^{\circ}$ or or $40,000^{\circ}$ Fahr. Let us be careful not to confound this diminution of energy with the reduction of temperature consequent on the dispersion of the rays as they recede from the photosphere during their course through the solar envelope. The reduction of temperature attending dispersion, obviously does not involve any diminution of mechanical 
energy. It would be waste of time to enter on any further demonstration in refutation of the extravagant assumption that a thermometer in contact with the photosphere would indicate some $12,000,000^{\circ} \mathrm{Fahr}$. higher temperature than that which we have established on the basis of the known distance and radius of the sun's photosphere, and the ascertained radiant intensity at the boundary of the earth's atinosphere. Nor need we point out the inconsistency of the doctrine that the sun's photosphere possesses less radiant power than incandescent terrestrial substances, such, for instance, as iron and carburetted hydrogen. But the advocates of high solar temperature may urge, that the law, agreeable to which the temperature of $4,000,000^{\circ}$ Fahr. has been determined, is mere theory, which, although true for distances of a few feet, may be wholly erroneous when the radiator is millions of miles away.

It has been one of the principal objects of my researches connected with solar heat, during the last three years, to endeavour to determine this question. Accordingly, the difference of intensity of solar radiation at midsummer and midwinter has been particularly observed. Fortunately, the eccentricity of the earth's orbit is sufficient to produce a marked difference of intensity at different seasons ; but, on the other hand, the varying depths of the atmosphere resulting from the varying inclination of the earth's axis, apart from the varying distance between the sun and the earth, presentserious obstacles. My observations as before mentioned have been conducted in lat. $40^{\circ} 42^{\prime}$, hence $17^{\circ} 12^{\prime}$ from the ecliptic at the summer solstice, and $64^{\circ} 12^{\prime}$ at the winter solstice. Accordingly, the depth of atmosphere has varied during the investigations in the rario of $\mathrm{I} \cdot 04$ to $2 \cdot 25$; thus rendering comparisons between the actual intensities very difficult. A series of observations made at different hours and seasons has ultimately cnabled me to construct the curve before referred to, defining the maximum intensity of the sun's radiant heat for all latitudes at the time when the earth passes the aphelion; likewise defining the retardation of solar intensity for all zenith distances not exceeding $75^{\circ}$. Fvidently an accurate knowledge of the solar intensity corresponding with given zenith distances removes the obstacles attending the varrying inclination of the axis of the earth. The variation of intensity consequent on the eccentricity of the earth's orbit has also been accurately determined for eacin day in the year. The detail not being immediately connected with the subject under consideration, it will suffice to state that actinometer observations conducted under very favourable circumstances, January 7, I $87 \mathrm{I}$, proved the sun's radiant heat to be $57^{\circ} 25^{\circ} \mathrm{Fahr}$, the zenith distance being $63^{\circ} \times 5^{\prime}$. Referring to the table, it will be seen that for equal zenith distance$63^{\circ} 15^{\prime}$-the temperature produced by solar radiation is only $51^{\circ} 77^{\circ}$ when the earth passes the aphelion. An increase of solar intensity of $57^{\circ} 25-5 I^{\prime} 77=5^{\circ} 48^{\circ}$, when the earth is in perihelion, has therefore been established. This important fact enables us to test on a grand scale the correctness of our assumption that the intensity of solar radiation diminishes in the inverse ratio of the area over which the rays are dispersed.

The aphelion distance of the earth being 218.1 times greater than the radius of the sun's photosphere, while the perihelion distance is 2109 times that radius, the temperatures produced by solar radiation at the boundary of the earth's atmosphere at midsummer and at midwinter, will be inversely as $218^{\circ} 1^{2}: 210^{\circ} 9^{2}$. Consequently, as the ascertained maximum temperature at the former period is $84^{\circ} 84^{\circ} \mathrm{Fahr}$, the temperature produced by solar radiation at the latter period will be $\frac{218.1^{2} \times 84^{\circ} 84^{\circ}}{210^{\circ} 9^{2}}=$ $9072^{\circ} \mathrm{Fahr}$. Let us ascertain if this theoretical temperature correspond with actual fact. Our table shows that the diminution of solar intensity attending the passage of the rays through the atmosphere, when the zenith distance is $63^{\circ} 15^{\prime}$, amounts to $15^{\circ} 43^{\circ}$ in addition to the diminution. of $17.64^{\circ}$ on the ecliptic, together $33^{\circ} 07^{\circ}$. Adding this to the temperature $57^{\circ} 25^{\circ}$, observed January 7,1871 , we establish the fact that the temperature at the boundary of the atmosphere is $90^{\circ} 32^{\circ}$ Fahr. Agreeable to the foregoing theoretical determination, the temperature ought to be $90^{\circ} 72^{\circ}$, difference $=04^{\circ} \mathrm{Fahr}$. This discrepancy is accounted for by the fact that the sky, although unusually clear, was not quite free from cirrus haze on the day of observation, as proved by the indication of the solar calorimeter, an instrument by which the presence of any obstruction in the atmosphere is ascertained with absolute certainty. In addition to the proof thus furnished in support of the theory on which our calculations are based, that the temperature at the surface of the sun's photosphere does not much exceed $4,000,000^{\circ}$ Fahr., other tests have been adopted with nearly identical results, an account of which, together with necessary delineations, has been published in Engincering. These tests prove that, unless the photosphere of the sun possesses relatively less radiating power than incandescent cast iron, or metallic substances coated with lampblack, and maintained at ordinary boiling heat, the temperature indicated by a thermometer "dipped inside the solar envelope in contact with the photosphere" will not exceed 4,100,000 deg. Fahrenheit.

Table sinowing the depth of atmosphere, and intensity of solar radiation, for each degree of zenith distance, when the earth passes the aphelion.

\begin{tabular}{|c|c|c|c|c|c|}
\hline 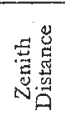 & 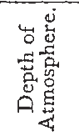 & 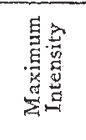 & 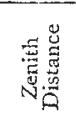 & 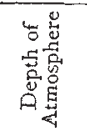 & 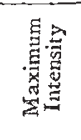 \\
\hline Deg. & & Fah. & Deg. & & Fah. \\
\hline 0 & r. 000 & $67 \cdot 20$ & 38 & $1 \cdot 265$ & $62 \cdot 1 \mathrm{I}$ \\
\hline I & I.000 & $67 \times 20$ & 39 & $\mathrm{I} \cdot 283$ & $6 I \cdot 8 I$ \\
\hline 2 & 1.000 & $67 \times 19$ & 40 & 1302 & $61 \cdot 50$ \\
\hline 3 & I'OOI & $67 \cdot 18$ & $4 \mathrm{I}$ & $\mathrm{I} \cdot 322$ & $61 \cdot 19$ \\
\hline 4 & I'002 & 67.16 & 42 & $\mathrm{I} \cdot 342$ & $60 \cdot 88$ \\
\hline 5 & I. 003 & $67 \cdot 12$ & 43 & $x \cdot 363$ & 60.57 \\
\hline 6 & I.005 & 67.08 & 44 & I 384 & $60 \cdot 25$ \\
\hline 7 & I 007 & $67^{\circ} 02$ & 45 & $I .406$ & 59.93 \\
\hline 8 & I'OIO & 66.96 & $4^{6}$ & I 431 & 59.60 \\
\hline 9 & r.or 3 & 66.90 & 47 & I 457 & $59 \cdot 25$ \\
\hline 10 & I.016 & $66 \cdot 84$ & 48 & 1.485 & 58.88 \\
\hline II & I '019 & 66.77 & 49 & 1.514 & $58 \cdot 51$ \\
\hline 12 & 1.023 & 66.70 & 50 & I. 545 & $58 \cdot 12$ \\
\hline 13 & I.027 & $66 \cdot 62$ & $5^{\mathrm{I}}$ & 1.577 & $57 \cdot 72$ \\
\hline 14 & I.03I & $66 \cdot 54$ & $5^{2}$ & 1612 & $57^{\circ} 31$ \\
\hline 15 & $1 \cdot 036$ & 66.44 & 53 & $I \cdot 648$ & 56.89 \\
\hline I6 & $I^{\circ}$ 04I & $66 \cdot 33$ & 54 & I.686 & $56 \cdot 46$ \\
\hline 17 & I 046 & $66 \cdot 2 I$ & 55 & $I \cdot 726$ & $56 \cdot 02$ \\
\hline 18 & I $05^{\prime} \mathrm{I}$ & 66.08 & 56 & $x \cdot 769$ & $55^{\circ} 5^{6}$ \\
\hline 19 & 1.057 & $65 \cdot 95$ & 57 & $\mathrm{I} \cdot 8 \mathrm{I} 5$ & $55^{\circ} \circ 9$ \\
\hline 20 & I 063 & 65.82 & 58 & $x \cdot 864$ & $54^{\circ} 60$ \\
\hline $2 \mathrm{I}$ & I 070 & 65.68 & 59 & I.916 & $54 \cdot 10$ \\
\hline 22 & 1.077 & 65.53 & 60 & I:970 & 53.58 \\
\hline 23 & I. 085 & 65.38 & $6 x$ & 2.037 & 53.05 \\
\hline 24 & I.093 & $65 \cdot 22$ & 62 & 2.098 & $52 \cdot 50$ \\
\hline 25 & $x \cdot 102$ & 65.04 & $\sigma_{3}$ & $2 \cdot 164$ & $5 I \cdot 90$ \\
\hline 26 & $I \cdot I I I$ & 64.86 & 64 & $2 \cdot 235$ & 5140 \\
\hline 27. & $I \cdot I 2 I$ & $64 \cdot 67$ & 65 & $2 \cdot 312$ & $50 \cdot 81$ \\
\hline 28 & $\mathrm{I} \cdot 132$ & 64.48 & 66 & $2 \cdot 398$ & $59 \cdot 20$ \\
\hline 29 & $I \cdot 14 \mathrm{I}$ & $64 \cdot 28$ & 67 & 2.490 & 49.57 \\
\hline 30 & $x \cdot 152$ & 64.07 & 68 & $2.59 \mathrm{I}$ & $48 \cdot 91$ \\
\hline $3 \mathrm{I}$ & $r \cdot 16_{4}$ & $63 \cdot 85$ & 69 & $27 \mathrm{OI}$ & $48 \cdot 25$ \\
\hline 32 & $I \cdot I 76$ & 63.63 & 70 & $2 \cdot 8 \bar{z} \mathbf{I}$ & 47.55 \\
\hline 33 & $I \cdot I 89$ & 63.40 & 71 & 2.952 & $46 \cdot 84$ \\
\hline 34 & I. 203 & $63 \cdot 16$ & 72 & 3097 & $46 \cdot 12$ \\
\hline 35 & $1 \cdot 217$ & 62.92 & 73 & 3.255 & $45 \cdot 37$ \\
\hline 36 & $x \cdot 232$ & $62 \cdot 67$ & 74 & 3.428 & $44^{\circ} 60$ \\
\hline 37 & $\mathrm{I} \cdot 248$ & $622^{\circ}$ & 75 & 3.624 & 4378 \\
\hline
\end{tabular}

J. ERICSSON 